\title{
CORROSION OF GLASS FIBRES IN ULTRA HIGH PERFORMANCE CONCRETE AND NORMAL STRENGTH CONCRETE
}

\author{
\#BARBORA HOLUBOVÁ, HELENA HRADECKÁ, MARIE NETUŠILOVÁ, TADEÁŠ GAVENDA, ALEŠ HELEBRANT
}

\author{
University of Chemistry and Technology Prague, Department of Glass and Ceramics, \\ Technická 5, 16628, Prague 6, Czech Republic \\ "E-mail: Barbora1.Holubova@vscht.cz
}

Submitted May 11, 2017; accepted July 10, 2017

\begin{abstract}
Keywords: Glass fibers, Corrosion, Concrete
Among other modern applications of glass fibres, there is a strong interest in their use as a strengthening agent for building materials. Alkali-Resistant (AR) glass fibres serving as ideal reinforcement for concrete proved to be very efficient against crack propagation at very early stages of the concrete setting process. However, a description of their behaviour in real cementous mixtures is missing because by now they have been studied mainly with various model tests simulating conditions of cementous environment. In this study two kinds of glass fibres (Anti-Crack HD and HP) were mixed into Normal Strength Concrete (NSC) and Ultra High Performance Concrete (UHPC) and stored under water for 28 days up to 1 year. Afterwards, chemical durability of the AR glass fibres was assessed mainly with SEM/EDS analysis. In general, the prepared samples did not demonstrate any signs of leaching or any other severe corrosion defects and they did not behave in a way suggested by the model tests, as reported in literature. In contrast to testing in high alkaline environment, no depleted corrosion layer rich in $\mathrm{Zr}$ and $\mathrm{Ca}$ was observed and functionality of the glass fibres remained unchanged.
\end{abstract}

\section{INTRODUCTION}

Ultra High Performance Concrete (UHPC) is a new type of concrete developed only in the last 30 years; it is a composite cement-based material with extremely high strength, long service life, high quality surface and minimum volume changes in the course of setting (drying shrinkage coefficient is below $5 \times 10^{-7}$ compared to $23 \times 10^{-7}$ for conventional concrete [1]). The most recognized parameter for definition of UHPC is compression strength, which shall be at least $150 \mathrm{MPa}$ and which significantly exceeds the highest strength class C100/115, as defined in ČSN EN 206-1/Z3 [2]. However, in practice the compression strength may be up to $250 \mathrm{MPa}$ [3] and under laboratory conditions it can be over $400 \mathrm{MPa}$. The minimum tensile strength is $7 \mathrm{MPa}$ [4], however, its usual value is over $15 \mathrm{MPa}$ [2]. Key factors that ensure exceptional mechanical properties of UHPC include, particularly, extreme compactness, efficient filling of space with individual particles of the aggregate and high homogeneity. These properties are ensured particularly by selection of proper qualities and quantities of the raw materials, while an important role is also played by the perfect production technology.

At present, UHPC is mostly used for bridge and engineering structures, architectural elements (stair stringers, facades), etc. $[5,6]$. Thanks to its exceptional properties, UHPC is suitable for special applications, e.g. for elements exposed to frost cycles, environment containing chlorides or other aggressive substances (e.g. load-bearing submarine structures) or for heavy duty applications (e.g. large format sidewalk pavers). It should be mentioned that, although the initial costs of UHPC might be higher than those of standard concrete (ca. 3 - 4 times), from the long-term viewpoint the material is more economical thanks to the minimum requirements for maintenance and thanks to the fact that it keeps sufficient mechanical properties for a significantly longer period of time - the service life of UHPC elements is usually estimated at 200 years [1].

Although UHPC is seen as a relatively new material, raw materials for its production are similar to those used for production of standard concrete, i.e. NSC (Normal Strength Concrete). The raw materials for UHPC are usually portland cement (the size of particles is ca. $15 \mu \mathrm{m}$ ), quartz sand (diameter of particles $150-600 \mu \mathrm{m}$, up to $1 \mathrm{~mm}$ ), ground quartz (diameter of particles $1-200 \mu \mathrm{m}$ ), microsilica (or "silica fume", diameter of particles up to $1 \mu \mathrm{m})$, superplastifiers and water $[1,5$, 7]. Microsilica is the UHPC component with the finest particles but it is very important - it helps to efficiently fill free space between bigger particles of the aggregate, it increases pozzolanic reactivity of the mixture of raw materials and, moreover, thanks to the round shape of its particles, it improves its flowability - and thus also placeability - of the concrete paste [5]. Apart from microsilica, it is also possible to add other fine-grained aggregates, e.g. fly ash or metakaolin. 
Another integral component of UHPC are dispersed fibres and therefore UHPC is sometimes also called UHPFRC (Ultra High Performance Fibre Reinforced Concrete). The fibres are added in order to supress formation or spreading of micro- and macro- cracks, which improves strength of the composite. However, improvement of mechanical properties is conditional on even distribution of the fibres in the concrete matrix. The fibres used for reinforcement include steel, organic, polymer (PP, PVA), carbon, mineral or glass microfibers, with the diameter up to $0.3 \mathrm{~mm}$ and their length is most frequently ca. $10 \mathrm{~mm}[2,8,9]$. For manufacturing of small components it is more convenient to use longer fibres ( $9-25 \mathrm{~mm}$ ), with the ratio of length to the diameter up to $60[1,2]$. The most frequently used fibres are those made of steel, however, application of glass fibres has been increasing in recent years. Glass fibres have sufficient modulus of elasticity but, in comparison with steel fibres, they have a lower price and also lower density. In comparison with similarly priced polymer fibres they have higher tensile strength (ca. $1700 \mathrm{MPa}$ ). Another advantage of UHPC reinforced with glass fibres are its aesthetic properties (thinner and lighter structures), which is important e.g. for architectural elements [2-11]. Rigaud in his study [10] showed that the ideal content of glass fibres is ca. 2 vol. \%, nevertheless, in practice, some materials contain up to 5 vol. \% of fibres.

The first experiments with fibres made of soda-lime glass were not successful due to their corrosion [11-13]. Majumdar and Ryder [14] used high-zirconium glass (16 wt. \% of $\mathrm{ZrO}_{2}$ ), identified as Alki-Resistant glass (AR-glass) that demonstrated higher alkaline resistance just thanks to the addition of network-forming $\mathrm{ZrO}_{2}$. This type of glass is still being used for production of glass fibres for concrete mixtures, however, not even fibres made of AR-glass are completely inert to the strongly alkaline environment and they may corrode [15-22].

Dissolution of glass can be described as dissolution of any other solid substance in three subsequent steps: the dissolution as such (i.e. surface reaction), subsequent transport of the dissolved components from the glasssolution interface and potential precipitation of reaction products. The dissolution is controlled by the slowest process. In the case of corrosion of glass fibres in concrete there is the process of dissolution of silica network but also precipitation of corrosion products, such as silicates, carbonates and aluminates. The inter-diffusion phenomenon, with regard to the content of alkaline ions in concrete, is usually negligible. More detailed analyses of the interaction between glass and water solutions are available e.g. in [23-28].

With regard to complexity of corrosion of glass fibres in concrete there is no general description of this process which depends on many parameters, particularly on specific compositions of the concrete matrix and of the fibres [15]. At present, there is no uniform standardized procedure for investigation of the interaction between the fibres and the concrete matrix. Many authors [15-22, 29-31] in their works deal with various model studies evaluating mechanical changes or overall degradation of concrete, however, the chemical interaction of glass fibres in real concrete mixtures has been rather neglected. In this work we have assessed corrosion mechanisms of two types of AR glass fibres that differed by their final treatment (dispersable/non-dispersable lubrication) in two concrete mixtures. One of them was NSC (Normal Strength Concrete) and the other was UHPC. The two types of concrete had different compositions and grain sizes of the raw materials which affected their important properties, such as compactness or open porosity and therefore one could expect their different effects on glass fibres mixed into them.

\section{EXPERIMENTAL}

Two types of commercial alkali-resistant glass fibres, Anti-Crack HD and HP, were selected for the tests, which had been previously used for model leaching tests in different types of alkali solutions with $\mathrm{pH}$ 10-14 in the first work of the authors [33]. Surface of the AntiCrack HD fibres was treated with dispersable lubrication (after mixing into a concrete mixture they fall apart into individual fibres), while one strand contains approximately 800 monofibres. Strands of Anti-Crack HP glass fibres were treated with non-dispersable antiabrasive lubrication (they remain undivided even after aggressive mixing with aggregate) and 1 strand contains approximately 100 monofibres. Both the types of the fibres have the same chemical composition, as indicated in Table I.

Table 1. Chemical composition of AR-glass fibres used for the experiments (XRF, [wt. \%]).

\begin{tabular}{lccccc}
\hline wt. \% (XRF) & $\mathrm{SiO}_{2}$ & $\mathrm{ZrO}_{2}$ & $\mathrm{Na}_{2} \mathrm{O}$ & $\mathrm{CaO}$ & $\mathrm{Al}_{2} \mathrm{O}_{3}$ \\
\hline Anti-Crack HD & 56.8 & 20.0 & 16.2 & 6.2 & 0.3 \\
Anti-Crack HP & 56.9 & 19.9 & 16.0 & 6.3 & 0.3 \\
\hline
\end{tabular}

In order to test chemical durability and corrosion kinetics two concrete mixtures were prepared with the two above-mentioned types of AR glass fibres. The first concrete mixture was regular concrete identified as NSC (Normal Strength Concrete), the second concrete mixture was UHPC concrete. Both the concrete mixtures were prepared from Czech made precursors and their preparation and casting into moulds (prisms sized $40 \times 40 \times 160 \mathrm{~mm}$ ) was carried out under the Czech standard ČSN EN 196-1 [32]. According to the manufacturer's recommendation, the content of AR glass fibres in the prepared concrete mixture was $0.6 \mathrm{~kg} \cdot \mathrm{m}^{-3}$ for HD fibres and $3.0 \mathrm{~kg} \cdot \mathrm{m}^{-3}$ for HP fibres. In the course of casting into moulds a part of glass fibres was placed 
into concrete mixtures in moulds in a higher density in the perpendicular and crosswise direction so that the fibres are situated approximately in one half of the prism volume and thus subsequently visible during the examination with microscopy (Figure 1a, b). After 24 hours of concrete setting in the air the prisms were taken out from the moulds and placed in water for 28 days (in the building industry it is the time for sufficient hardening of the concrete, after which standard strength tests of concrete are performed), and then for 3 , 6 and 12 months.

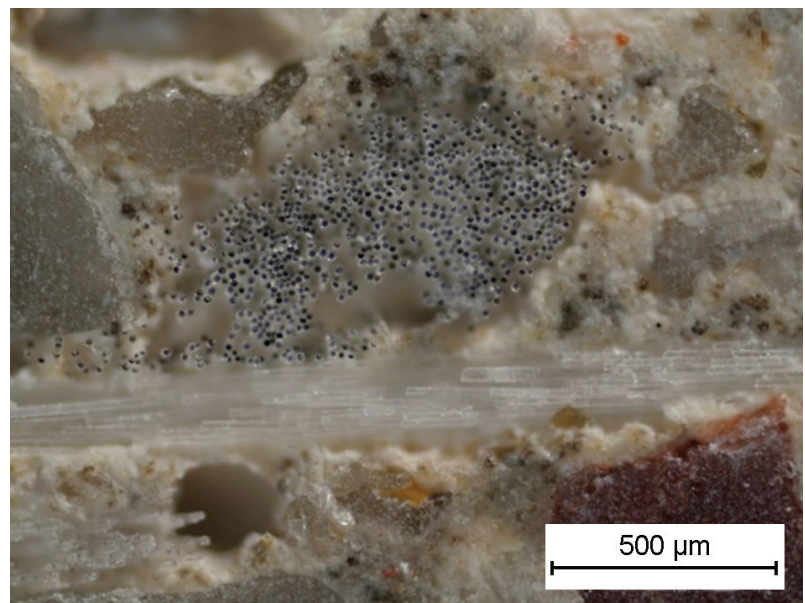

a)

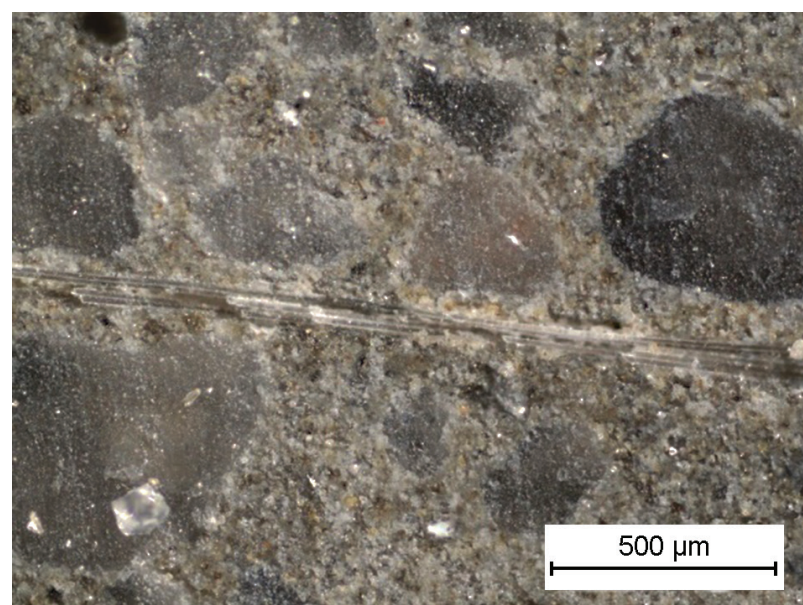

b)

Figure 1. Placement of AR glass fibres in NSC (a) and UHPC (b) concrete mixture (optical microscope).

Samples of concrete were taken out from the water bath after the respective periods of time, cut on a diamond saw to slices $5 \mathrm{~mm}$ thick and analysed with optical microscopy (Olympus BX 51 with the camera Olympus E-600) and scanning electron microscopy SEM with EDS (Hitachi S-4700). XRF analysis of the chemical composition of glass fibres was carried out on ARL 9400 XP.

\section{RESULTS AND DISCUSSION}

\author{
Visual evaluation
}

To evaluate corrosion phenomena the samples were initially examined with optical and scanning electron microscopy. As there were no cracks, no volume or visually significant corrosion on the samples, not even after 1 year of exposure of concrete prism to water, we have shown below for comparison more detailed images from the scanning microscopy (SEM) only for the samples exposed to water for 28 days and 1 year. In the course of evaluation of the results it was also found out that the type of lubrication (dispersable or non-dispersable) had no effect on the appearance and composition of the fibres throughout the testing time - results of both types of the fibres were comparable and therefore we have provided below only images and evaluations for one type of the fibres (Anti-Crack HD).

Images of the initial glass fibres, before they were mixed into concrete mixtures, are shown in Figure 2.

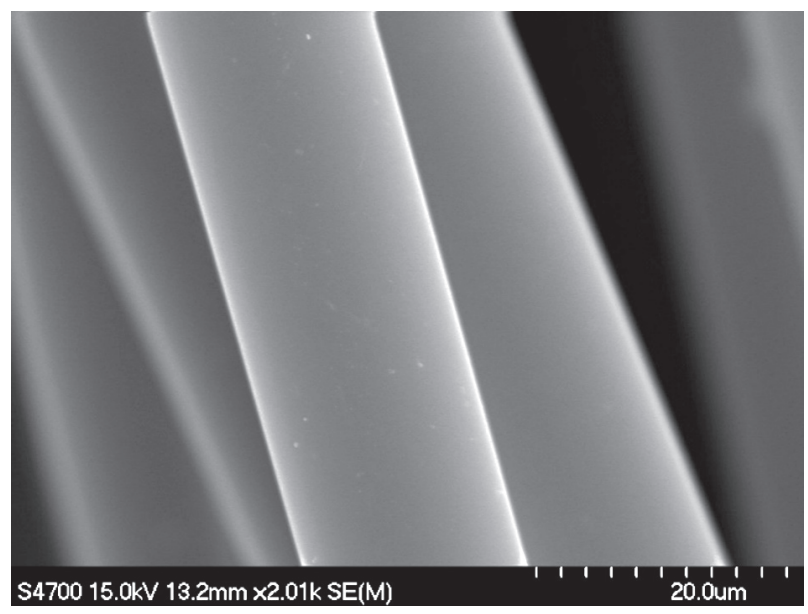

Figure 2. Anti-Crack HD glass fibres before they were mixed into a concrete mixture (SEM).

Figures 3 and 4 show SEM images of fibres mixed into NSC and UHPC concrete respectively, after they were immersed in water for 28 days and 1 year. The images show significant differences between glass fibres mixed in both types of concrete. In NSC there is a visible layer of corrosion products on the fibres, as early as after 28 days, formed by the reaction of glass fibres with the so-called pore solution of concrete mixture (Figure 3, at the top). After one year of exposure of concrete samples to water, i.e. in the conditions when the sample cannot dry up and the glass fibres are continually exposed to the pore solution with high $\mathrm{pH}$, corrosion products on the surface of glass fibres grow and a visible, homogeneous and continuous layer with a "spongy" structure is formed on the surface (Figure 3 bottom). However, the diameter of the glass fibres does not change significantly and the fibres do not disintegrate. 


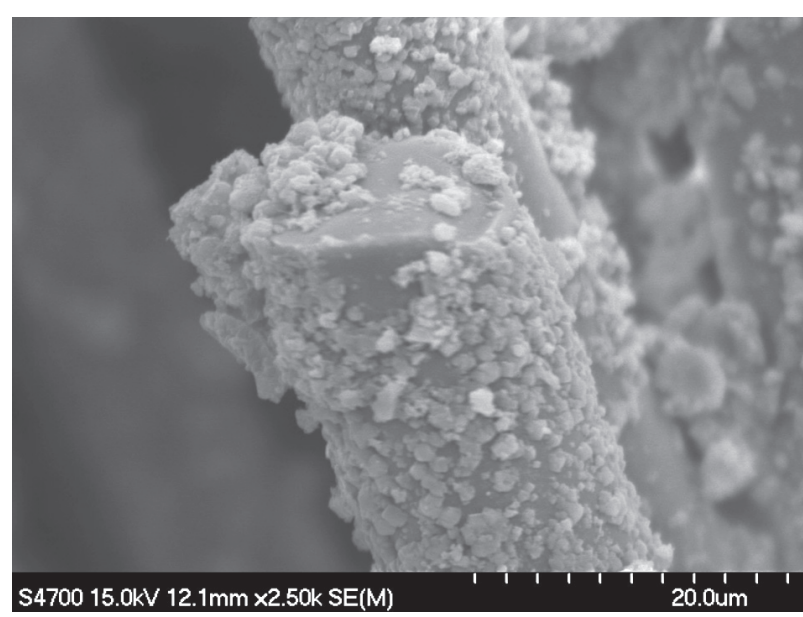

a) 28 days

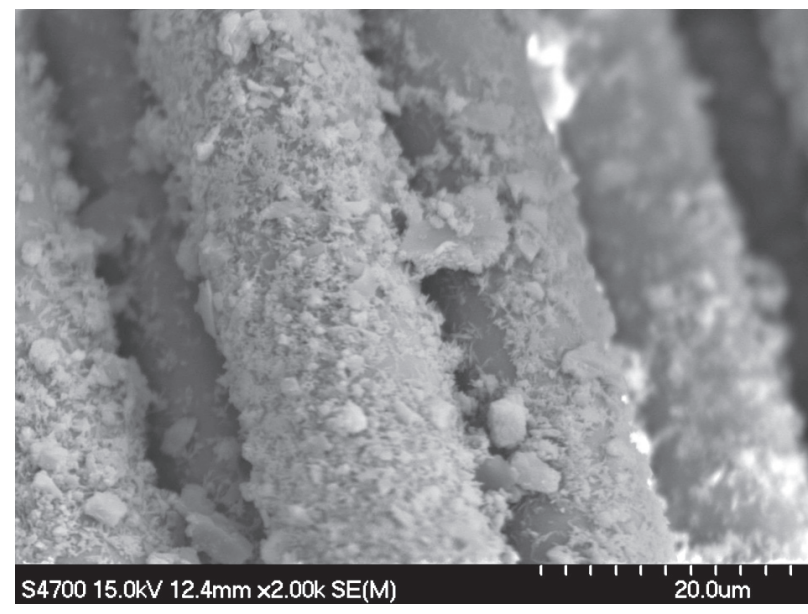

c) 1 year

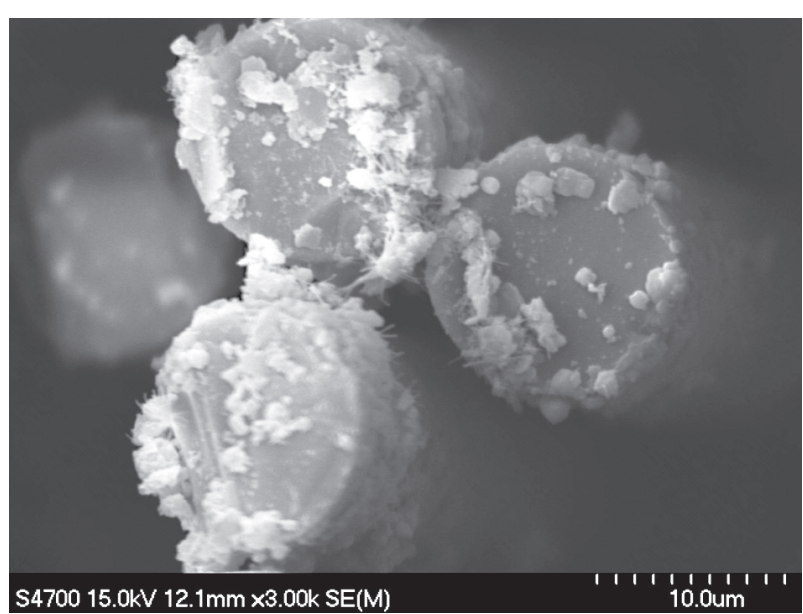

b) 28 days

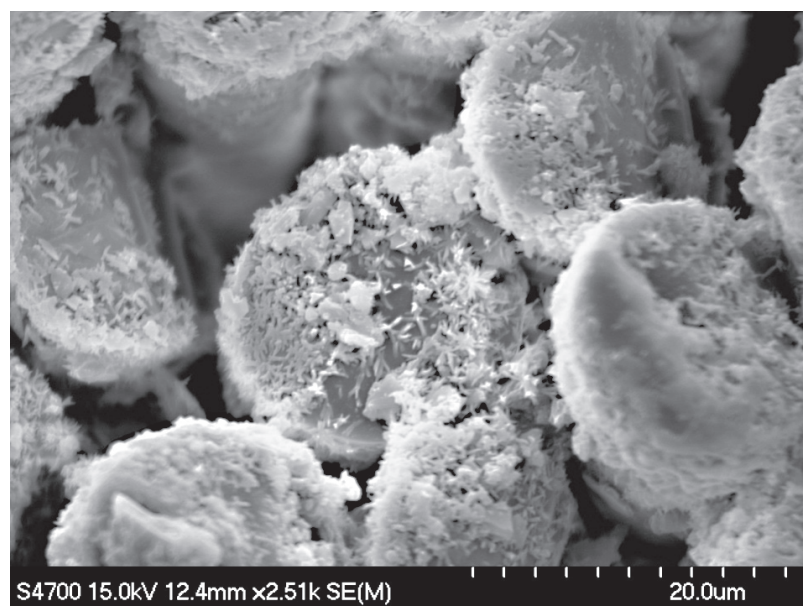

d) 1 year

Figure 3. HD glass fibres in the NSC concrete mixture after being immersed in water for: 28 days (a, b); 1 year (c, d).

Glass fibres mixed in the UHPC concrete mixture (Figure 4) and immersed in water for different periods of time did not change significantly. Samples of the glass fibres immersed in water for 28 days were not significantly damaged by development of corrosion products, similarly as the glass fibres immersed in water for 1 year. The glass fibres remained compact. In both the cases there were less corrosion products on the fibre surface and they did not form a continual layer as it was the case with the fibres in the NSC concrete mixture. The reason of the difference is probably the low value of absorbability caused by higher compactness of UHPC concrete, with a smaller proportion of open porosity which is up to 3 times higher in NSC concrete mixtures (for data and measurements see [32]).

\section{Evaluation of the corrosion processes}

The corrosion products were evaluated by means of SEM/EDS analysis focusing on corrosion products developed on the surface of glass fibres, as well as on the surface of the fibres as such, before and after they are placed in a concrete mixture and after such concrete samples were immersed in water for 28 days and for 1 year. For comparison purposes, we have also provided chemical composition of the bulk glass fibres, as identified by the XRF analyses. We have also presented results of HD fibres mixed in concrete mixtures.

Results of the analysis of glass fibres mixed in NSC concrete mixtures and immersed in water for 28 days have shown formation of corrosion products rich in $\mathrm{CaO}$ with a very low content of $\mathrm{ZrO}_{2}$, while the composition of the fibre surface did not significantly change in comparison with the original fibre (Figure 5). On the other hand, NSC concrete samples immersed in water for 1 year had mainly precipitated products on the surface of the fibres, rich in $\mathrm{SiO}_{2}(>80$ wt. \%) and also with very low content of $\mathrm{ZrO}_{2}$ (Figure 6). Even though the whole glass fibre was nearly completely covered with precipitated products, EDS analysis of the exposed surface suggests that even after one year of immersion in water no sufficient change occurred in the chemical composition of the surface (slight decrease of $\mathrm{SiO}_{2}, \mathrm{ZrO}_{2}$ and $\mathrm{Na}_{2} \mathrm{O}$; slight increase of $\mathrm{CaO}$ ). As the fibres do not 


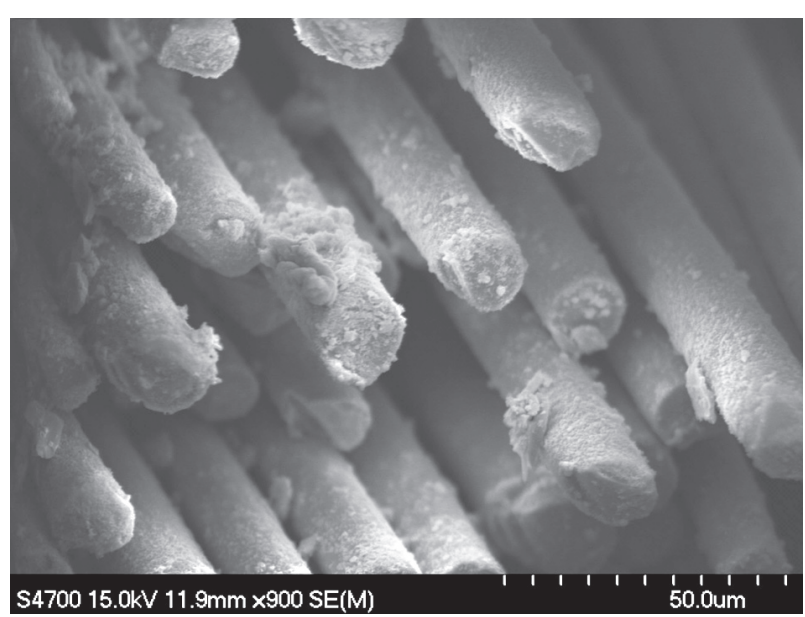

a) 28 days

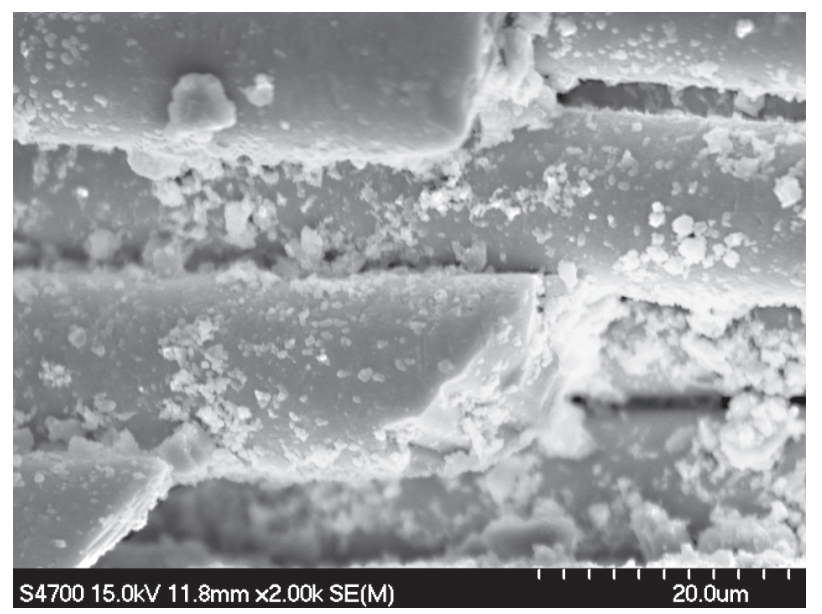

c) 1 year

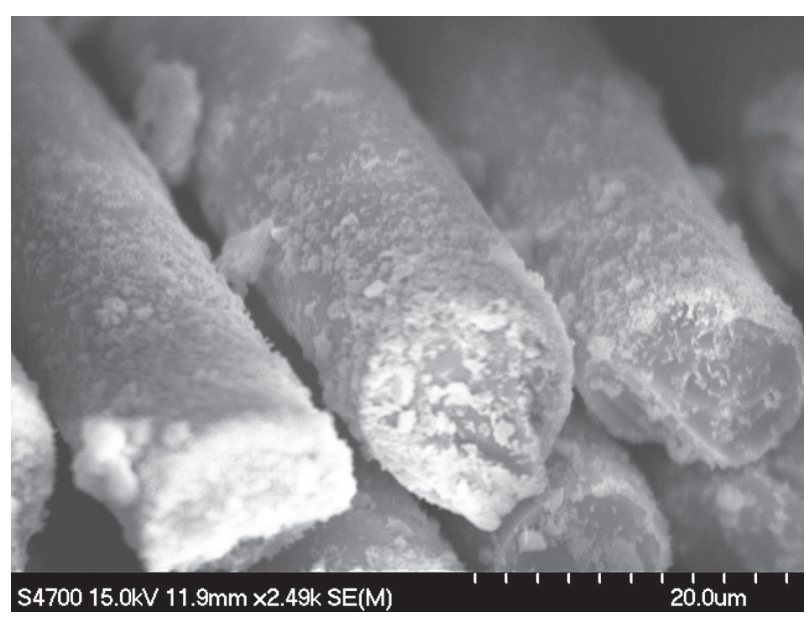

b) 28 days

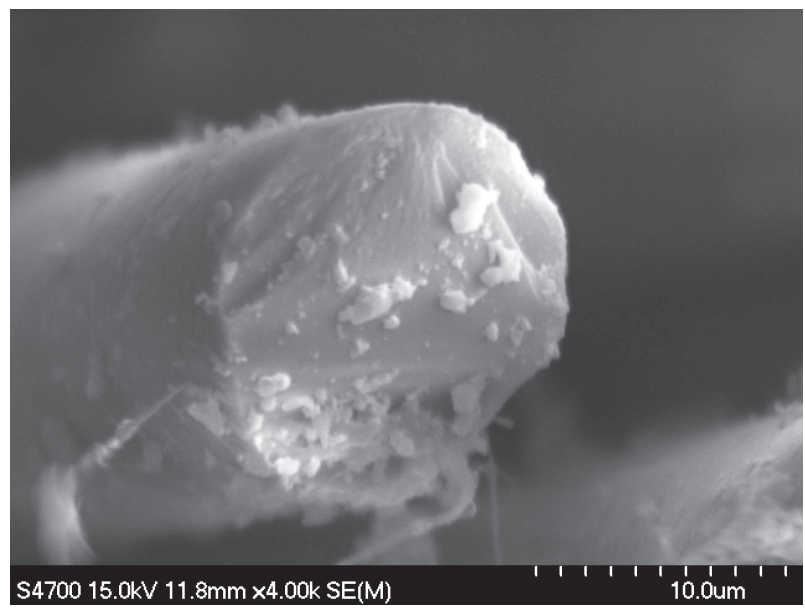

d) 1 year

Figure 4. HD glass fibres HD in the UHPC concrete mixture after being immersed in water for: 28 days (a, b); 1 year (c, d).

disintegrate and look compact (see Figure 3) and as their diameter is approximately the same as that of the original fibres $\left(\mathrm{d}_{\mathrm{fib}} \approx 14-15 \mu \mathrm{m}\right)$ and the increase is only due to the precipitated products $\left(\mathrm{d}_{\mathrm{fib}+\mathrm{prec}} \approx 16-21 \mu \mathrm{m}\right)$, it is possible to conclude that the layers are not made up of corrosion products of glass fibres but they consist of materials that come from the surrounding concrete matrix and precipitate on or adhere to the fibres.

HD fibres in the UHPC concrete mixture immersed in water for 28 days and 1 year did not demonstrate any visually homogeneous corrosion layer. Results from EDS analyses of the samples after 28 days in water did not significantly differ from those exposed to water for 1 year. The surface of the fibres (exposed to water for 28 days and 1 year) did not change significantly, even though there was some slight reduction of $\mathrm{SiO}_{2}, \mathrm{ZrO}_{2}$, $\mathrm{Na}_{2} \mathrm{O}$ and an increase of $\mathrm{CaO}$. Analyses of the precipitates (after exposure for 28 days and 1 year) have shown an increased content of $\mathrm{CaO}$ (Figure 7). In the samples exposed to water for 28 days there were less corrosion products but they were more diverse (CaO 11 - 45 wt. \%; $\mathrm{SiO}_{2} 37$ - 59 wt. \%). The products precipitated or adhered

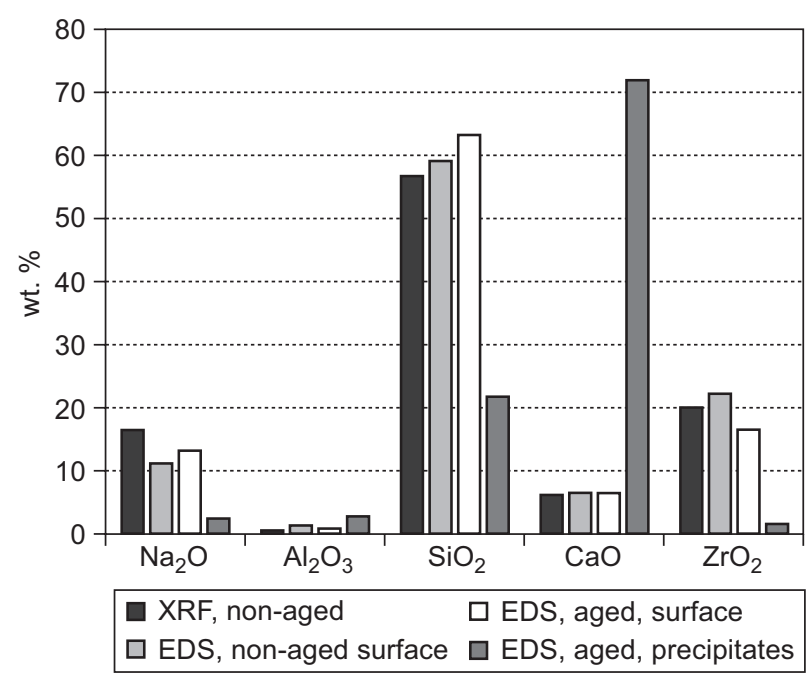

Figure 5. HD glass fibres in the NSC concrete mixture and immersed in water for 28 days - diagram of measured values from XRF, EDS. 
on the surface, similarly as it was in the case described above, also probably come from the surrounding environment of the concrete mixture. Precipitated products on the surface of samples immersed in water for 1 year contained also other components - K, Al, Ti (probably from the added slag).

The differences in the results of EDS analyses of fibres in NSC and UHPC concrete are probably caused by different behaviour of concrete mixtures in water. UHPC concrete, thanks to the higher micronization and higher purity of the employed materials, features high compactness, very low porosity and even reduced alkalinity of the pore solution [1-11]. After the setting the glass fibres and the UHPC concrete matrix did not demonstrate such chemical changes as it was the case with NSC concrete, in which, due to its character and

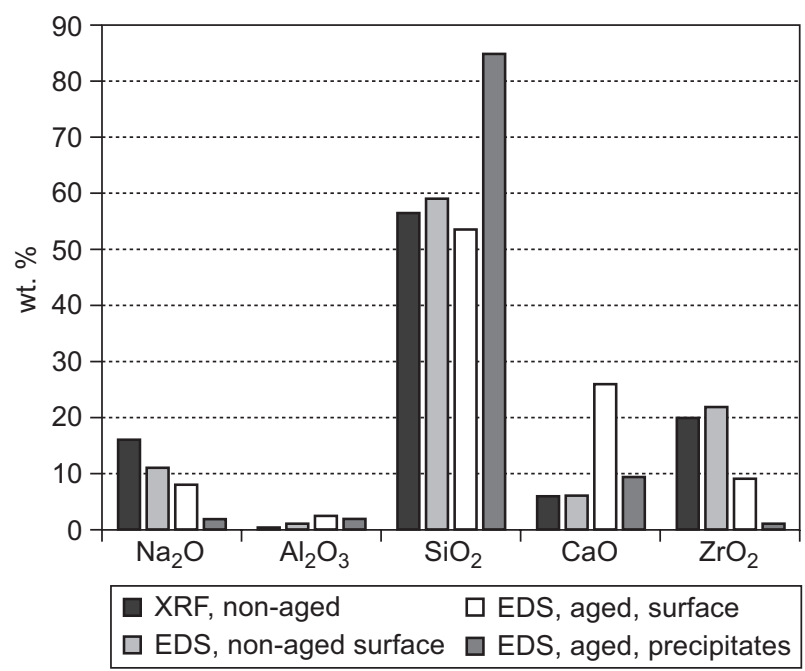

Figure 6. HD glass fibres in the NSC concrete mixture immersed in water for 1 year - diagram of measured values from XRF, EDS.

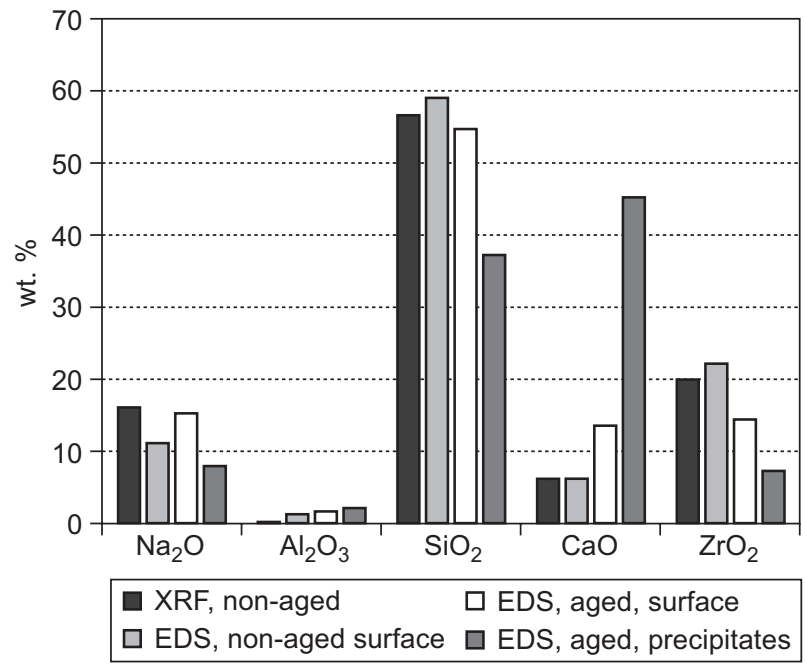

Figure 7. HD glass fibres in the UHPC concrete mixture immersed in water for 1 year - diagram of measured values from XRF, EDS. structure, the pore solution can be transported also after hardening of the samples and thus also the concrete matrix changes its chemical composition. Nevertheless, as mentioned before, neither the character nor the function of glass fibres in both the types of concrete were significantly damaged.

However, the above provided results of tests of chemical durability of glass fibres mixed into real concrete mixtures are not in direct conformity with results of model studies of alkali corrosion of AR glass fibres, as reported in literature [15-22, 29, 30]. During the model tests most authors performed leaching of fibres in water solutions of individual hydroxides or in mixtures of such hydroxides (the so-called pore solution) at $\mathrm{pH} 10$ to 14 and at increased temperatures (up to $80^{\circ} \mathrm{C}$ ). Some reduction of the fibres was found during the tests (the diameter of the fibres decreased). At the same time, the authors observed precipitated calcium products on the surface of fibres (in case that $\mathrm{Ca}(\mathrm{OH})_{2}$ was present in the solution), as well as partial dissolution of the surface (of the silica network) and re-precipitation of silicates, while the surface layer always contained also substantial quantities of $\mathrm{Zr}$ (45 - 50 wt. \%). Therefore the authors believed that a siliceous layer is formed on the surface of fibres, rich in $\mathrm{Zr}$ and $\mathrm{Ca}$, and it may subsequently slow down the corrosion rate of the fibres. However, results of tests with real concretes have shown that in reality the prevailing processes are those of concrete dissolution (of sand grains etc.) and potential leaching of calcium ions in the proximity of fibres, rather than corrosion of the glass fibres. Re-precipitated products of such reactions (siliceous or calcium-siliceous products) subsequently deposit on the surface of fibres and thus they may prevent their corrosion. In real concretes there was no significant corrosion on the surface of fibres or dissolution of the fibres (reduction of the diameter). Therefore the reported model tests, in comparison with the real life exposure, seem to be excessively aggressive.

\section{CONCLUSIONS}

The presented study has verified and proved good chemical durability of AR glass fibres used for reinforcement in the course of setting and drying of concrete mixtures. Glass fibres, despite the presence of precipitated products, did not disintegrate, not even after being immersed in water for one year, and they continued to perform their original function. Corrosion of fibres in concrete is not significantly dependent on the type of lubrication (dispersable on the HD fibres or non-dispersable on the HP fibres). On the fibres mixed in standard concrete mixtures there were high quantities of precipitated products rich in $\mathrm{Si}$ or $\mathrm{Ca}$. In UHPC the quantities of corrosion products were significantly lower and they were rich in $\mathrm{Ca}$. With regard to the fact that the diameter of the fibres did not change and the content of 
Zr was low it is possible to conclude that the precipitated products probably came from the surrounding environment of the concrete matrix. In comparison with actual processes in real concrete mixtures, earlier model studies $[15-22,33]$ seem to have used too aggressive conditions.

\section{Acknowledgement}

This study was accomplished with the financial support from specific university research (MSMT No 20SVV/2017).

\section{REFERENCES}

1. Fládr J., Bílý P., Vodička J. (2016): Experimental Testing of Resistance of Ultra-high Performance Concrete to Environmental Loads. Procedia Engineering, 151, 170-176. doi:10.1016/j.proeng.2016.07.366

2. Myšičková L. (2012). Vlastnosti, zkoušení a využití UHPC v konstrukcích, bakalář́ská práce (Properties, testing and use of UHPC in structures), bachelor thesis. Brno University of Technology.

3. Dils J., Boel V., de Schutter D. (2013): Influence of cement type and mixing pressure on air content, rheology and mechanical properties of UHPC. Construction and Building Materials, 41, 455-463. doi:10.1016/j.conbuildmat. 2012.12.050

4. Abbas S., Soliman A.M., Nehdi M.L. (2015): Exploring mechanical and durability properties of ultra-high performance concrete incorporating various steel fibre lengths and dosage. Construction and Building Materials, 75, 429-441. Doi: 10.1016/j.conbuildmat.2014.11.017

5. Ahlborn T.M., Peuse E.J., Li Mission D. (2008). Ultrahigh performance concrete for Michigan bridges: Material performance. Michigan Technology University, Michigan.

6. National Precast Concrete Association (2013). Ultra-high performance concrete (UHPC) - Guide to manufacturing architectural precast UHPC elements. CARMEL. WWW: http://precast.org/wp-content/uploads/2015/02/UHPCWhite-Paper.pdf

7. Graybeal B.A. (2006). Material Property Characterization of Ultra-High Performance Concrete, (No. FHWAHRT-06-103). The Federal Highway Administration, Turner-Fairbank Highway Research Center.

8. Šajna A. (2010). Ultra High Performance Fibre Reinforced Concrete (UHPFRC) for durable rehabilitation of bridges. WWW: http://onlinepubs.trb.org/onlinepubs/shrp2/LLB_ Sajna.pdf

9. Coufal R., Vítek L.J. (2012): První použití UHPC ve formě transportbetonu v ČR (The first use of UHPC in truckmixed concrete in the Czech Republic). Materiály pro stavbu, 9, $57-59$.

10. Rigaud S., Chanvillard G, Chen J. (2012). Characterization of bending and tensile behaviours of ultra-high performance concrete containing glass fibres, in ParraMontesinos G.J., Reinhardt H.W., Naaman A.E. (Eds.): Proceedings of High Performance Fibre Reinforced Cement Composites 6, Rilem Bookseries, pp. 373-380.

11. Bentur A., Midness S. (2007). Fibre Reinforced Cementitious Composites. Taylor\&Francis.
12. Scheffler C. et al. (2009): Aging of alki-resistant glass and basalt fibres in alkaline solutions: Evaluation of the failure stress by Weibull distribution function. Journal of Non-Crystalline Solids, 355, 2588-2595. doi:10.1016/j. jnoncrysol.2009.09.018

13. Yilmaz V.T. (1992): Chemical attack on alki-resistant glass in a hydrating cement matrix: characterization of corrosion products. Journal of Non-Crystalline Solids, 151, 236-244. doi:10.1016/0022-3093(92)90035-I

14. Majumdar A.J. (1971). Improvements in or relating to glass fibres and compositions containing glass fibres (National Research Development Corp), UK Patent I 243972.

15. Wang W. et al. (2014): Durability of an Ultra High Performance Fibre Reinforced Concrete (UHFRC) under progressive aging. Cement and Concrete Research, 55, 1-13. doi:10.1016/j.cemconres.2013.09.008

16. Graybeal B. (2010). Simultaneous structural and environmental loading of a UHPC component, Federal Highway Administration of USA. (No: FHWA-HRT-10-055). The Federal Highway Administration, Turner-Fairbank Highway Research Center. https://www.fhwa.dot.gov/publications/research/infrastructure/structures/10055/index.cfm

17. Jaffer S.J., Hansson C.M. (2008): The influence of cracks on chloride-induced corrosion of steel in ordinary Portland cement and high performance concrete subjected to different loading conditions. Corrosion Science, 50, 3343 3355. doi:10.1016/j.corsci.2008.09.018

18. Mills R.H. (1981): Preferential precipitation of calcium hydroxide on alkali-resistant glass fibres. Cement and Concrete research, 11, 689-697. doi:10.1016/0008-8846 (81) $90027-2$

19. Coricciati A., Corvaglia P., Mosheyev G. (2009): Durability of fibres in aggressive alkaline environment, in Banks W.M., Wisnom M.R. (Eds.): Proceedings of $17^{\text {th }}$ International Conference on Composite Materials (ICCM-17), Institute of Materials, Minerals and Mining, 30:F1:4, pp. 1-10. http://iccm-central.org/Proceedings/ICCM17proceedings/Themes/Behaviour/AGING,\%20MOIST\%20\&\%20 VISCOE\%20PROP/F1.4\%20Coricciati.pdf

20. Larner L.J., Speakman K., Majumdar A.J. (1976): Chemical interaction between glass fibres and cement. Journal of Non-Crystalline Solids, 20, 43-74. doi: 10.1016/0022-3093 (76) $90107-1$

21. Makishima A., Tsutsumi M., Shimohira T., Nagata T. (1983): Characterization of Insoluble Layers Formed by $\mathrm{NaOH}$ Attack on the Surface of a $\mathrm{ZrO}_{2}-$ Containing Silicate Glass. Journal of the American Ceramic Society, 66(8), C139-C140. doi:10.1111/j.1151-2916.1983.tb10112.x

22. Chakraborty M., Das D., Basu S., Paul A. (1979): Corrosion behaviour of a zirconia containing glass in aqueous acid and alkaline media and in a hydrating cement paste, Journal of Cement Composites, 1, 103-152.

23. Helebrant A. (1997): Kinetics of corrosion of silicate glasses in aqueous solutions. Ceramics-Silikáty, 41, 147-151.

23. Melcher M., Schreiner M. (2006): Leaching studies on naturally weathered potash-lime-silica glasses. Journal of Non-Crystalline Solids, 352(5), 368-379. doi:10.1016/j. jnoncrysol.2006.01.017

25. Helebrant A., Jiřička A., Jiřičková J. (2004): Corrosion of Glass. Glass Science and Technology, 77C, 85-94.

26. Clark D. E., Zoitos B.K. (1991). Corrosion of Glass, Ceramics and Ceramic Superconductors. Noyes Publications. 
27. Sanders D.M., Hench L.L. (1973): Mechanism of glass corrosion, Journal of the American Ceramic Society, 56, 373-377. doi:10.1111/j.1151-2916.1973.tb12689.x

28. Hench, L. L. (1975): Characterization of glass corrosion and durability. Journal of Non-Crystalline solids, 19, 2739. doi:10.1016/0022-3093(75)90067-8

29. Nourredine A. (2011): Influence of curing conditions on durability of alkali-resistant glass fibres in cement matrix. Bulletin of Materials Science, 34(4), 775. doi:10.1007/ s12034-011-0194-1

30. Payá J., Bonilla M., Borrachero M. V., Monzó J., PerisMora E., Lalinde L. F. (2007). Reusing fly ash in glass fibre reinforced cement: A new generation of high-quality GRC composites. Waste Management, 27(10), 1416-1421. doi:10.1016/j.wasman.2007.03.014
31. Chen J., Chanvillard G. (2012). UHPC composites based on glass fibers with high fluidity, ductility, and durability, in: Ultra-High Performance Concrete and Nanotechnology in Construction. Kassel University Press. pp. 265-272.

32. Pernicova R., Dobiáš D., Mandlík T. (2015): Mechanical properties of UHPC with different kinds of glass fibres, in: Proceedings of the International Conference Fibre Concrete. Czech Technical University Prague. pp. 353-359. 33. Helebrant A., Hradecká H., Holubová B., Brázda L., Netušilová M., Zlámalová-Cílová Z. (2017): Kinetics of processes modeling corrosion of glass fibres mixed into concrete. Ceramics-Silikáty 61, 163-171. doi: 10.13168/ cs.2017.0012 